\title{
ARTE NOS MUROS E PAREDES COMO NECESSIDADE DE REPRESENTAÇÃO HUMANA
}

\author{
Susete Rodrigues da Silva ${ }^{1}$
}

\section{RESUMO}

O homem sente a necessidade de expressar suas ideias e registrá-las desde sempre. O desejo de desenhar, falar, narrar e contar esteve presente na humanidade desde o tempo das cavernas, depois nos muros e nas paredes. Por isso, neste escrito, teve-se como objetivo versar sobre a necessidade do homem se expressar por meio do desenho, em especial, do grafite e de todo 0 entorno dos conceitos de sua própria história. Para isso, recorreu-se à metodologia qualitativa, com base em revisões bibliográficas, além de relatos e de vivências empíricas do próprio autor que, após ser mãe, sentiu o desejo de compreender a necessidade humana de pintar e de desenhar nas paredes. Como resultado deste estudo, os alunos de escola pública realizaram obras de arte, focando no desenho como expressão de suas arte e modo de viver e ver o mundo.

Palavras-chave: Arte na Escola; Grafite; Liberdade de Expressão.

\begin{abstract}
Man feels the need to express his ideas and record them forever. The desire to draw, speak, narrate and tell has been present in humanity since the time of the caves, then on the walls and walls. For this reason, the objective of this writing was to discuss the need for man to express himself through drawing, in particular, graphite and everything around the concepts of his own history. For this, qualitative methodology was used, based on bibliographic reviews, in addition to reports and empirical experiences of the author himself, who, after being a mother, felt the desire to understand the human need to paint and draw on the walls. As a result of this study, students from public schools carried out works of art, focusing on drawing as an expression of their arts and way of living and seeing the world.
\end{abstract}

Keywords: Art at School; Graphite; Freedom of Expression.

\section{RESUMEN}

El hombre siente la necesidad de expresar sus ideas y registrarlas para siempre. El deseo de dibujar, hablar, narrar y contar, ha estado presente en la humanidad desde la época de las cuevas, luego en las paredes y las paredes. Por lo tanto, este escrito tenía como objetivo hacer frente a la necesidad de que el hombre se expresara a través del dibujo, en particular, del grafito y del conjunto en torno a los conceptos de su propia historia. Para ello, se utilizó la metodología cualitativa, basada en revisiones bibliográficas, además de informes empíricos y experiencias del propio autor que, después de ser madre, sintió el deseo de entender la necesidad humana de pintar y dibujar en las paredes. Como resultado de este estudio, los estudiantes de escuelas públicas realizaron obras de arte, centrándose en el dibujo como expresión de sus artes y forma de vivir y ver el mundo.

Palabras clave: Arte en la Escuela; Grafito; Libertad de Expresión. 


\section{INTRODUÇÃO}

Como professora da Rede Municipal de São Paulo, pude vivenciar o que já havia vivido na infância: pouco ou nenhum espaço reservado para a criança se expressar livremente. Ainda, nos dias de hoje, podemos encontrar desenhos feitos às escondidas em portas de banheiro, carteiras, paredes e muros das escolas. Mas, por que as crianças e os jovens sentem a necessidade de desenhar nas paredes? Talvez, este sentimento esteja relacionado ao que observou Baudrillard nos grafites dos guetos novaiorquinos que expressavam o sentimento de dizer: "Eu existo".

Por que as crianças sentem tanta necessidade de expressar e registrar nas paredes? Este sentimento está relacionado ao sentimento humano conhecido pelo homem desde as cavernas?

Por que, para muitos adultos da minha geração e de outras, desenhar significa um castigo?

É muito natural, socialmente estimulado, adultos impedirem as crianças de desenharem nas paredes de suas casas e escolas, espaços que a criança passa boa parte ou toda parte de sua infância. O que ainda resta são as ruas, mas as crianças da era da modernidade brincam em condomínios ou ficam trancadas em creches e escolas no tempo que não ficam em sua casa. Depois, quando adolescentes ganham a liberdade das ruas e a necessidade de expressão aflora com mais força, por isso o grafite se justifica em primeiro lugar e depois por ser uma expressão de arte. Desta forma, a sociedade neste formato contribui para que as crianças não expressem livremente seus sentimentos através do desenho e se tornem adultas que tenham dificuldades de desenhar.

O Pedro Aurélio é filho de mãe atriz, contadora de histórias e arteeducadora e o pai Saulo Di Tarso, artista plástico e curador. Teve liberdade de expressão muito cedo, mas essa relação não foi tão simples e tranquila, eu imaginava que iríamos reservar uma parede para o Pedro pintar e desenhar. Fui surpreendida pela necessidade expansiva que o Pedro sentia em pintar as paredes, não foi uma, foram muitas paredes pintadas e confesso que entrei em conflito, sofri muito, pois não sabia o que fazer reprimir, muitas vezes o fiz, 
mas fui encorajada pelo espírito libertador do Saulo que concedia ao Pedro o direito de desenhar, experimentar novos materiais, espaços e me mostrar novos caminhos.

Penso que hoje a criança deveria ter o direito preservado de desenhar livremente, como em Pompéia, onde os homens, mulheres e crianças tinham a liberdade de escrever e desenhar nas paredes.

As paredes das casas e das escolas podem reservar espaço para a expressão infantil. Exemplo positivo de influência escolar é o relato do grafiteiro Jerry Batista que nos conta como a escola teve papel fundamental em sua formação artística. Sejamos os delbatores do nosso tempo, as paredes podem ser pintadas novamente, mas o gesto infantil não pode ser vívido posteriormente.

Este texto não tem a pretensão de responder às questões que são levantadas, tem caráter reflexivo, até porque não tenho respostas para elas, mas a partir dessas indagações e da necessidade de realizar um trabalho de finalização de disciplina do mestrado, que realizei no Instituto de Artes da UNESP, resolvi pesquisar e conhecer um pouco sobre o grafite. Procurei localizar historicamente o grafite no mundo, na cidade de São Paulo e apresento o grafite dos artistas Crânio e Mundano e de Jerry Batista do Espaço Coletivo 132, escolhidos das ruas da cidade por um olhar e uma leitura, de tantas outras que podem ser feitas.

\section{BREVE HISTÓRIA DO GRAFITE}

O homem sente a necessidade de expressar suas ideias e registrá-las desde sempre. $O$ desejo de desenhar, falar, narrar e contar esteve presente na humanidade desde o tempo das cavernas, depois nos muros e paredes.

O grafite é o mais antigo registro gráfico do homem. De acordo com historiadores, a presença do grafite ocorre desde a Grécia Antiga e em Pompéia. Em Pompéia, é possível reconhecer expressões simbólicas de massa que se fundam em padrões específicos. Entre o povo, predomina o cotidiano da sua práxis e não a idealização da arte erudita, a língua falada se opõe ao "latim" ensinado na escola da elite, à associação em grupo e ao anonimato, se opõem, ainda, ao individualismo, à escrita de estilete, do pincel e da parede, não da pena, 
do papiro e dos livros. Podemos observar, então, a oposição do popular ao erudito.

As paredes de Pompéia testemunham grafites, escritos pelo povo comum, com caráter público, por todo lado os grafiteiros ocupam os espaços disponíveis. As intervenções murais contêm traços únicos no contexto da criação cultural popular. A grafitagem feita na época era numerosa, na sua maioria, era anônima e provinha de todos os grupos populares da cidade, desde camponeses a artesãos, de gladiadores a lavadores, escravos e feirantes. O ritmo de grafitagem era tão intenso que os grafites eram apagados pelos delbatores que ao pé da letra significa: "que tornam a parede branca".

De fato, as paredes de Pompéia testemunham a ocupação pelos grafiteiros de todos os espaços disponíveis: ali encontramos cerca de uma inscrição por adulto, homens e mulheres, livres e escravos, feitas nos últimos momentos da cidade, o que significa dez mil inscrições.

Através das intervenções murais antigas, podemos observar a liberdade do homem comum daquela época que, através das paredes, podia publicar seus textos, seus desenhos e fazer sua propaganda no que seria a grande imprensa da época. Os temas dos grafites eram diversos, os mais frequentes eram de campanhas eleitorais; de poemas amorosos, jocosos, satíricos, irônicos; assinaturas; insultos; caricaturas e trocadilhos espalhavam-se por todas as paredes.

A letra utilizada pelo povo nos grafites era a letra de mão ou cursiva, tais letras tendem a ter traços alongados o que permitia ter uma verdadeira iconografia na simples escrita, além da flexibilidade e uma estética maleável. As letras latinas, que conhecemos como maiúsculas eram utilizadas nas grandes inscrições oficiais: eram letras da erudição, esculpidas na rocha ou batidas em metal.

As inscrições mais frequentes feitas nas paredes pompenianas eram com estilete: graphium (ponta com que se escrevia em superfícies duras, traçando sulcos). As inscrições pintadas (tituli picti) feitas com pincéis eram em número menor e na sua maioria feitas por grafiteiros remunerados.

O grafitismo pompeniano, fenômeno não erudito por definição, não científico no sentido de Salviano, exprime, sempre de forma lírica, uma ideia que está presente na cabeça do scriptor. Isto se passa não apenas em nível do

Tendências Multidisciplinares: Investigação, Método e Ciência 
conteúdo como também da forma. O conteúdo remete ao contexto cultural específico do autor da mensagem, contexto este que engloba fatores de classe social, sexo, idade, posição ideológica, autoimagem, entre outros (FUNARI, 1989).

Como podemos observar, o grafite naquele período já estava ligado ao popular, expressando através da arte dos murais traços únicos do contexto social do grafiteiro, de forma poética a leitura do cotidiano, a expressão estética da vida comunitária. O grafismo popular desde o início teve um caráter coletivo, através das paredes externas podia-se retratar a vida concreta, as paixões, as ilusões, as lutas e conflitos. $O$ artista se constitui num verdadeiro poeta, planeja, executa e compartilha publicamente com o imaginário coletivo sua percepção da sociedade, possibilitando a qualquer um o exercício da capacidade poética e artística. Podemos afirmar que a arte do grafite sempre teve um papel democrático desde então.

$\mathrm{Na}$ contemporaneidade, o registro oficial do aparecimento do grafite foi em Paris, em maio de 1968, a partir da opressão política surge um movimento que resultou em rebeliões de ruas, aparecendo nos muros da cidade grafites com palavras de ordem: La liberte c'est Le crime qui contient lês crimes, ou de protesto La Bourgeoisie n'a pás d'autre plasir que celui de lês dégrader tous, depois mensagens de amor e humor descompromissadas, anônimas, gratuitas e extremamente livres.

Em 1972, passados quatro anos dos registros parisienses, em New York, nas paredes dos guetos, muros da periferia e pelos trens de metrô, nos ônibus e caminhões os grafites começam a fazer parte da cena cotidiana. Os grafites ao ganharem o espaço de viagem pelos transportes públicos da cidade amedrontam a população mais elitizada e afugentam os turistas. Este movimento foi perseguido pela sociedade, através da polícia, que tentava combater a ação denominada de vandalismo. Muitos artistas foram presos e, numa grande contradição, outros levados às importantes galerias, bienais e museus de arte, não só nos Estados Unidos como no mundo todo.

De acordo com Jean Baudrillard, os grafites de New York não eram de conteúdo nem político e nem pornográfico, apenas nomes e sobrenomes, ou talvez pseudônimos, seguidos de endereços, nomes e números de ruas de jovens que sentiam grande necessidade de expressar sua existência na cidade, 
registrando a presença através dos grafites que iam roubando a cena. Provenientes dos guetos nova-iorquinos, esta rebelião consistiria em dizer: "Eu existo, eu sou tal, eu habito esta ou aquela rua, eu vivo aqui e agora" ${ }^{3}$

Esta rebelião ganhou espaço e transformou-se em movimento ganhando espaço pelo mundo como um modismo em ascensão. Um dos exemplos mais marcantes foi a cidade de Berlim que viu seu muro, de 4,5 m de altura por 166 $\mathrm{km}$ de extensão ser preenchido por centenas de milhares de imagens ao longo do tempo. Construído em 1961, para impedir a fuga dos berlinenses do leste, 0 muro começa a receber as primeiras inscrições na década de 80, como forma de protesto e revolta da população e artistas locais.

Poemas, provérbios e advertências ocuparam o muro inicialmente, depois foram surgindo figuras humanas, rostos, paisagens, animais e esqueletos, símbolos de paz como a pomba e a Estátua da Liberdade, que na sua maioria compunham um discurso visual de protesto à presença do muro, conhecido internacionalmente como Muro da Vergonha. Os artistas na sua maioria eram desconhecidos do grande público, mas era frequente a visita de artistas renomados como o grafiteiro norte-americano Keith Haring.

\section{O GRAFITE EM SÃO PAULO}

Em São Paulo, por volta de 1976 aparecem às primeiras inscrições nos muros da cidade, a expressão aparecia de forma anônima e insistente provocando a curiosidade da população, depois se descobriu que significava a divulgação de uma nova raça de cães. A partir daí, os muros começaram a receber poemas que dialogavam com a cidade, como: Ôi Muro! Bi Olhei Gamei Gostei!. Na sequência, os muros começaram a receber as imagens. As primeiras imagens registradas são a bota, a televisão, a pantera de Alex Vallauri, um etíope que viveu pouco tempo em Nova York e escolheu nossa cidade para viver. Foi o primeiro artista plástico a registrar sua marca gestual nos muros da cidade de São Paulo. Era um andarilho, não tinha carro e adorava perambular pelas ruas de São Paulo, audacioso grafitava tanto a noite como durante o dia.

A famosa bota, que bem representava seu espírito andarilho fora extraída da fábrica de carimbos Dulcemira Ltda, utilizada para impressão em anilina de sacos de armazéns, padarias, lojas em geral. Os alvos prediletos de Vallauri 
eram muros, fachadas de loja, postes que rapidamente recebiam suas imagens. Depois da bota que ficou conhecida na cidade, o artista deixou outras marcas como a imagem da pantera negra, dos quadrinhos Jungle Jim de Alex Raymond, o jacarezinho da grife Lacoste, a televisão, o carrinho de supermercado.

As imagens impressas nos muros da cidade, através da técnica do stencil e spray eram produzidos em série com fidelidade e competiam com as outras imagens publicitárias da época. Veja a leitura de Décio Pignatari sobre esta questão: "repare que coisa interessante: seria muito bonito captar em fotografia a cidade entre duas escrituras. Em cima, todos os luminosos, embaixo as sprayações, daria para comparar todo o investimento, caríssimo, que são os luminosos (e que também, montam um espetáculo belíssimo no mundo urbano, especialmente no alto dos edifícios) com as pichações luminosas, embaixo, como se fosse LUZ e NÃO-LUZ.

A NÃO-LUZ monta um sistema de escritura nas paredes: a NÃO-VENDA. Isto é, um mundo puramente cultural, espiritual, opondo-se ao mundo das vendas, e a cidade no meio." (FONSECA; RAMOS, 1994).

A ideia de cidade poluída pelos grafites e pelas pichações nasce neste período. As imagens do grafite passam a competir com o produto anunciado, surge então o protesto de muitos comerciantes que alegam serem os grafiteiros "poluidores" do espaço. Este pensamento mudou, nos dias de hoje, a sociedade paulistana aprova a lei da cidade limpa que fez os comerciantes, contrariados, tirarem suas propagandas. E o respeito à arte de rua vem crescendo, exemplo disto, foi a reação da população paulistana em não aceitar que a prefeitura apagasse o mural da Avenida 23 de Maio. O prefeito Kassab, diante da manifestação popular, teve que contratar os grafiteiros Os Gêmeos, Nunca, Nina, entre outros, para refazerem o mural, apagado na sua gestão.

Nos anos 80, um grupo de jovens universitários e acadêmicos inspirados numa história de Oswald de Andrade criam o coletivo "Tupinãodá", entre eles estavam: Milton Sogabe, Jaime Prades, Eduardo Duar, José Carratu e Cezar Teixeira, entre outros. Neste período, realizaram muitas performances de intervenção urbana, sendo que muitas delas eram ações com grafitagens.

De acordo com Jaime Prades, as intervenções do "Tupinãodá", tinham um caráter político, pautadas no contexto dos anos 80 , expressavam a luta pela democracia, pelo fim dos regimes militares, pelo direito ao voto, com as "Diretas 
Já”.

\begin{abstract}
O grupo tinha uma visão politizada e o fato de ir para a rua é muito político, totalmente político, mesmo que seja um ato inconsciente, acaba tendo repercussão política porque mexe com a comunidade... com o grafite, o indivíduo não está entrando pelo circuito, está entrando pela rua, e então é mais viril, tem mais a ver com esporte. Era uma espécie de Sarau Modernista. Não que fosse um simples devaneio, pelo contrário, tinha que ter um apoio (PIGNATARI, apud RAMOS, 1994).
\end{abstract}

Seguindo as ideias dos artistas deste século que viam na arte uma linguagem modificadora das relações homem/imagem/meio ambiente, o grupo foi influenciado pelas ideias de Duchamp, que já pregava a arte enquanto ideia, Andy Warhol, que levava o cotidiano para as artes e principalmente nos estudos Jean Duduffet, que compreendia que a arte enquanto forma deveria ser pesquisada das crianças, dos loucos, e enquanto suporte nos grafites das paredes. E entre os brasileiros, o grupo teve influências do performático Hélio Oiticica e do polêmico multimídia, precursor das performances no Brasil, Flavio de Carvalho, a quem o grupo reservava admiração especial.

Outro marco na história do grafite paulistano são os murais do túnel da Rebouças, um dos principais pontos que liga as principais avenidas da cidade, "umbigo paulistano", com centenas de siglas espalhadas pela sua grande extensão, o túnel tem sido espaço de disputa entre as "gangs", para ter uma imagem gravada nesse espaço com ou sem autorização da prefeitura. Desde 1987, quando o túnel foi ocupado pelo coletivo Tupínãodá, e até os dias de hoje, o espaço passou a representar um ícone para os grafiteiros e pichadores paulistanos.

O grafite tem forte ligação com o Hip Hop. Para esse movimento, o grafite é a forma de expressar toda a opressão que a humanidade vive principalmente os menos favorecidos, refletindo a realidade das ruas.

Anterior ao Grafite, a pichação pode ser considerada um protografite ${ }^{7}$, que parte de um processo mais anárquico de criação, onde a agressão ocupa lugar privilegiado. O pichador através de vários tipos de suportes: muros, topos de prédios, monumentos, igrejas, escolas, placas de trânsito, espaços sacralizados, não pede licença e insere sua marca. Expressa mensagens provocativas, 
através do gesto descompromissado com o estético e com a forma.

$O$ ato de pichar é um rito da juventude que necessita de vivências perigosas e cheias de adrenalina. Através das marcas deixadas e o nome expresso nos espaços da cidade o autor emite o desejo de sair do anonimato e dizer "eu existo". Para muitos artistas a pichação é necessária e possibilita a passagem para o grafite, além de alimentar o processo criativo. Veja o que disse Juneca "Tudo começou com a pichação, foi assim que eu comecei a interferir na cidade; com o amadurecimento, comecei a desenvolver o desenho" (TV Cultura, canal $2: 11 / 05 / 93)$.

Hoje, nas principais cidades do mundo, o conceito de "streetart" vem ganhando cada vez mais força e reconhecimento, por parte do público, das autoridades locais e crítica especializada, se fazendo presente nas ruas, nas principais galerias de arte e museus.

O grafite foi e continua sendo uma das mais importantes expressões da arte contemporânea, da rua para o mundo, ocupando importantes espaços como Moma nos EUA e Tate Modern na Inglaterra. Na cidade de São Paulo, tem tido grande destaque nas galerias e museus, teve sua primeira mostra institucional em Museu, em 2006, no Museu Afro Brasil, com curadoria de Saulo di Tarso e Emanoel Araujo e participações de Speto, Nunca, Kboco, Onesto, Ciro Schuneman e Daniel Melim. No ano de 2009, ocorreu no Mube - Museu Brasileiro da Escultura, a primeira Bienal de Grafitti Fine Art, por iniciativa de Binho, Tinho, Sergio Poato e Sergio Franco, além de várias exposições coletivas e individuais espalhadas pela cidade, como exemplo, a exposição dos Os Gêmeos na galeria da FAAP e outros espaços.

O grafite é uma expressão artística vigorosa e audaciosa "que nasce na rua", porém deixa de ser uma arte marginal quando ocupa espaços de arte, o que preocupa muitos artistas. "Para eles, ao entrar em uma sala de exposições, o Grafite perde seu caráter mais significativo de estar na rua, deixa de ser uma representação de streetart", se transforma em outra representação artística.

\section{A ESCOLHA DO GRAFITE E O COLETIVO 132}

Quando foram apresentados os temas para desenvolver o trabalho de finalização da disciplina "Poéticas Contemporâneas: A Poesia Brasileira da Era 
Pós-Verso e suas relações com as Artes Visuais" Professor Omar Khouri, escolhi falar sobre Grafite. Escolher um Grafite que além da imagem tivesse códigos gráficos para a análise, não era tarefa simples, porém bastante estimulante. A análise feita se norteia em estudos dos signos e conceitos da semiótica, na comunicação dos signos e significados e nas funções poéticas e metalinguística que os grafites escolhidos expressam.

Passei os meses de novembro e dezembro de 2011, escolhendo as imagens. A intenção era escolher alguma imagem na baixada do Glicério ou no bairro do Cambuci por fazer parte do trajeto que mais utilizava no cotidiano, além de serem bairros que possuem grafites de importantes artistas, mas a escolha dos grafites foi feita no bairro da Aclimação, próximo ao Centro Cultural São Paulo. Em uma tarde chuvosa, descompromissada com a escolha do grafite e preocupada com as tragédias ocorridas por fortes chuvas, fui surpreendida pela poética do grafite-instalação "Poeta Palhaço", de Jerry Batista, meus olhos se fixaram na imagem, não pude parar e passei semanas tentando localizá-lo, pensei que estivesse apagado, passei olhando pelo mesmo trajeto várias vezes e nada. Era como se o poeta tivesse brincando de esconde-esconde. Depois de muito procurar, quase desistindo, eu o reencontrei. Ao pesquisar pude descobrir que o grafite era de Jerry Baptista, pertencente ao Coletivo 132, também na Aclimação. A imagem escolhida impressionou os meus sentidos. Veja o que diz Isaac Epstein:

\footnotetext{
A transmissão de significados constitui o fluxo intersubjetivo pelo qual circula a cultura. A experiência vivida, o real sentido, percebido ou compreendido, o mundo do real ou do imaginário, das teorias científicas ou dos mitos, enfim, da vigília ou do sonho, é mediado de homem a homem por entes concretos capazes de impressionar nossos sentidos: os signos (EPSTEIN, 1990).
}

O espaço Coletivo 132 foi demolido era uma casa ateliê onde cinco artistas com ideias e objetivos em comum residiam, para pesquisar, estudar e desenvolver sua arte interagindo com a cultura e as paisagens paulistanas. Os artistas utilizavam materiais de descarte encontrados nos centros urbanos, visando à reciclagem e à conservação do meio ambiente como conceito básico da sustentabilidade. O Coletivo é formado pelos artistas: Enivo, Tché Ruggi, Rafael Sliks, Jerry Batista e Zumi e pela equipe de produção Guilherme Provenzano e Matheus Avila, que além da proposta coletiva possuem trabalhos 
individuais com experiências, estilos e técnicas de cada artista e ao mesmo tempo sofrendo influências do coletivo.

Jerry Batista nasceu no Grajaú, região afastada do centro da cidade, e em entrevista conta que desde criança desenhou. A escola pública foi um espaço de importante motivação, ali socializava suas criações. A influência aos temas ambientais vem deste período, conta que as aulas de biologia eram in loco, os alunos observavam a natureza, a represa e, assim, iam aprendendo os conteúdos apresentados pelo professor. Quando tinha entre 14 e 15 anos entrou em contato com o grafite pela primeira vez: "Eu estava indo comprar pão na padaria e vi dois meninos grafitando, em 95, aquilo brilhou no meu olho e pensei assim vou poder pintar para muitas pessoas..." - Entrevista realizada no coletivo $132 \mathrm{em} \mathrm{11/01/2011.}$

Em seguida montou um coletivo chamado $A F R O$, em parceria com Nigaz e outros doze integrantes. Os temas pintados eram sociais, motivados pelo RAP, músicas de Taíde e dos Racionais MC. Com o parceiro Nigaz, começou a vir para o centro de São Paulo e ter contato com os artistas: Os Gêmeos, Binho, Tinho, entre outros. Lembra que pegavam o ônibus e passavam por baixo da catraca para comprar um cachorro-quente. O ônibus fazia o percurso da Avenida 23 de Maio e toda aquela expressão pintada influenciou seu trabalho. Do Tinho, recebeu influência das questões sociais e dos Gêmeos o estímulo da criação do universo que o poeta-palhaço faz parte.

O artista apresenta através deste Universo um contexto em que os conflitos são resolvidos sem violência. Ele acredita que a agressividade presente entre os meninos, veem da influência dos super-heróis. Seus trabalhos são apresentados em duas fases: Cidade dos Homens e Cidade dos Índios. 
Imagem 1. Poeta- Palhaço, grafite-instalação de Jerry Batista

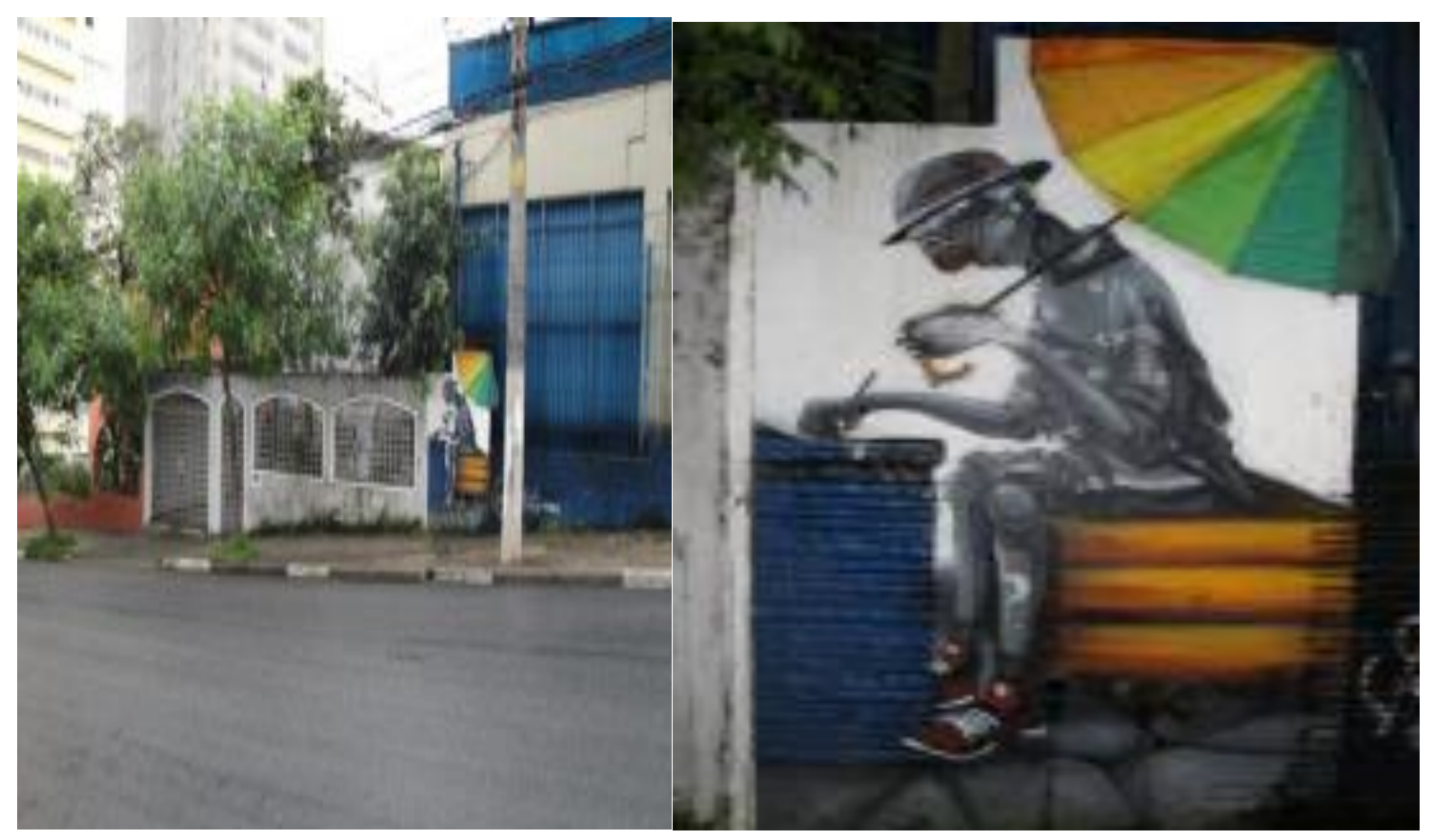

Fonte: Arquivo pessoal (2021).

Suas intervenções são inseridas nas ruas da grande cidade, desde 1996. Traz em seus traços uma convivência com o meio ambiente, com as questões sociais, com um universo próprio que criou e lembranças remanescentes do circo. Utiliza materiais descartados, encontrados nas ruas. Sua intenção é contribuir para a vida em harmonia.

O grafite instalação poeta-palhaço de Jerry Batista teve o muro autorizado pelo dono, encontra-se na Rua Pires da Mota, entre os números 1141 e 1211 , foi fotografado no dia 12 de janeiro de 2011, por volta das 15h30. O artista utilizou tinta spray, tecido e restos de um guarda-chuva.

Para o artista que é filho de nordestinos, o signo guarda-chuva tem um sentido bastante importante, ele representa a proteção do sol e o desejo da chuva para os que vivem na seca.

O poeta seria o guardião destes povos. Para os dias de hoje, na cidade de São Paulo, podemos fazer a leitura que este guardião protege das chuvas que tanto castigam nos últimos tempos. E ainda protege o texto, o mundo das letras 


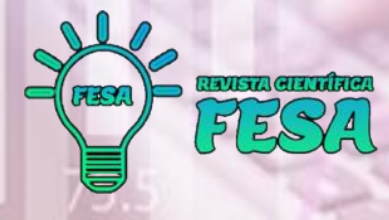

que o poeta tem como foco principal: escrever.

\section{O GRAFITE DE CRÂNIO E MUNDANO}

O mural dos grafiteiros Crânio e Mundano não existe mais, foi fotografado dia 12 de janeiro de 2011, na Rua João Maia, entre os números 37 e 45, por volta das $15 \mathrm{~h}$. O mural foi feito em um tapume de um imóvel que foi demolido.

Imagem 2. Mural de Crânio e Mundano

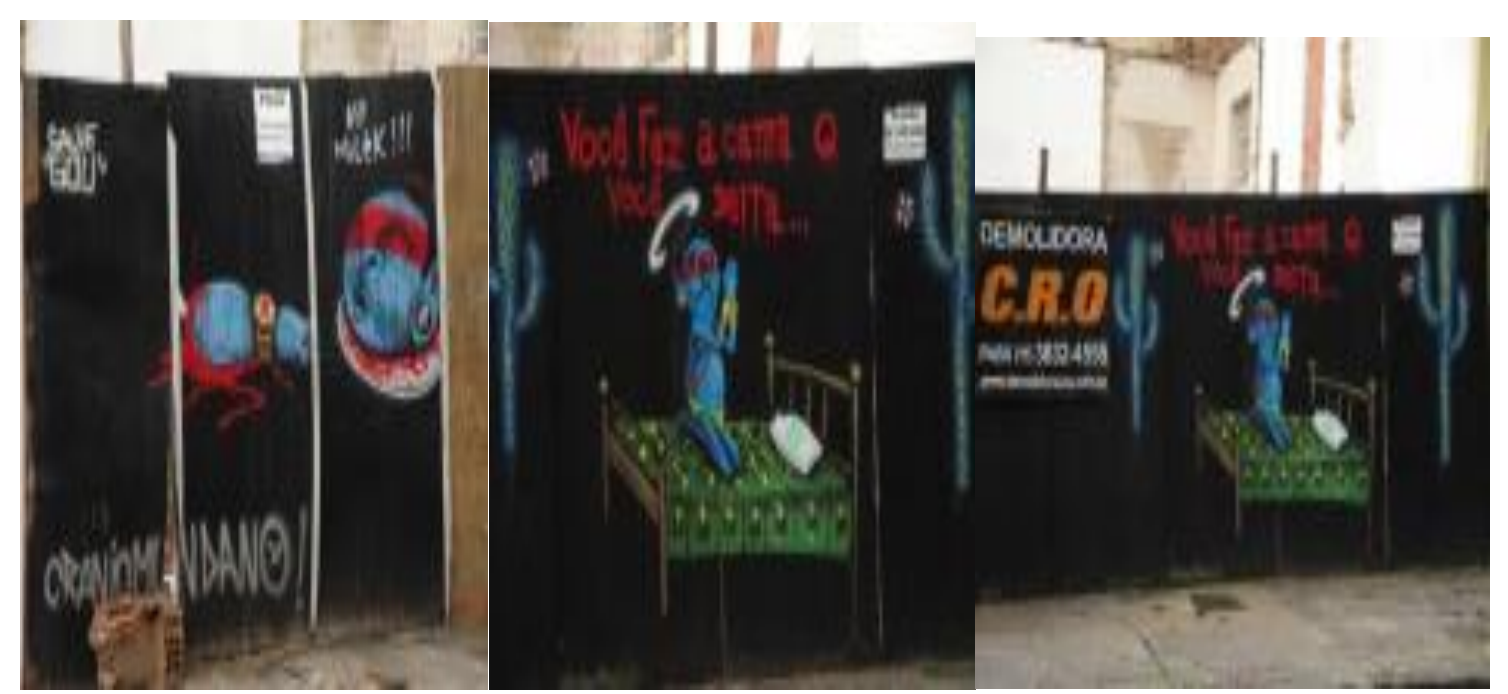

Fonte: Arquivo Pessoal (2011).

O prédio que ali se encontrava era uma antiga editora que preservava a bela arquitetura do antigo casarão que, não resistiu aos tempos modernos. $O$ grafite faz uma crítica social muito forte ao monopólio das construtoras que mandam na cidade e destroem casas antigas, casarões e pequenas vilas, na ânsia capitalista e devastadora de modernizar a cidade.

A cena narra à trajetória do filho do Brasil, "índio-negro", que usa alargador na orelha, colar de candomblé, tanga amarela e pulseiras que podem ser algemas. Reza ou ora prostrado na cama capitalista cheia de cifrões. Seu olhar se direciona ao céu, parece pedir a Deus, Oxalá ou Tupã proteção ou libertação, ou será que pede perdão ou redenção aos "céus"? A cena está entre dois cactos, representação de um deserto urbano, que me remete a mesma ideia da selva de pedras.

A pintura foi feita em spray e os artistas utilizaram um fundo preto com o 


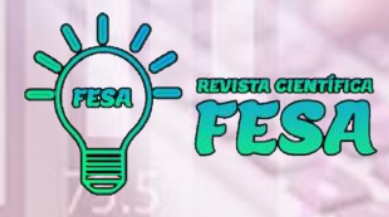

sentido de fortalecer a ideia de peso e tensão. Podemos observar que houve intervenção de pichação no mural. Quem pichou está cumprimentando e compartilhando com as ideias de Crânio e Mundano. As pichações são: "Salve "GOU" e "Ah! Mulék!".

\section{PINTURAS DE PEDRO AURÉLIO NAS PAREDES}

Pedro Aurélio começou a desenhar nas paredes antes de completar dois anos de vida. Foi em uma das refeições, quando comia beterraba. De repente, ele se levantou com o alimento nas mãos e foi até a parede e desenhou, encantou-se com a descoberta da cor e a possibilidade de desenhar.

Imagem 3. Desenhos livres colados na porta, pintados com tinta e com batom

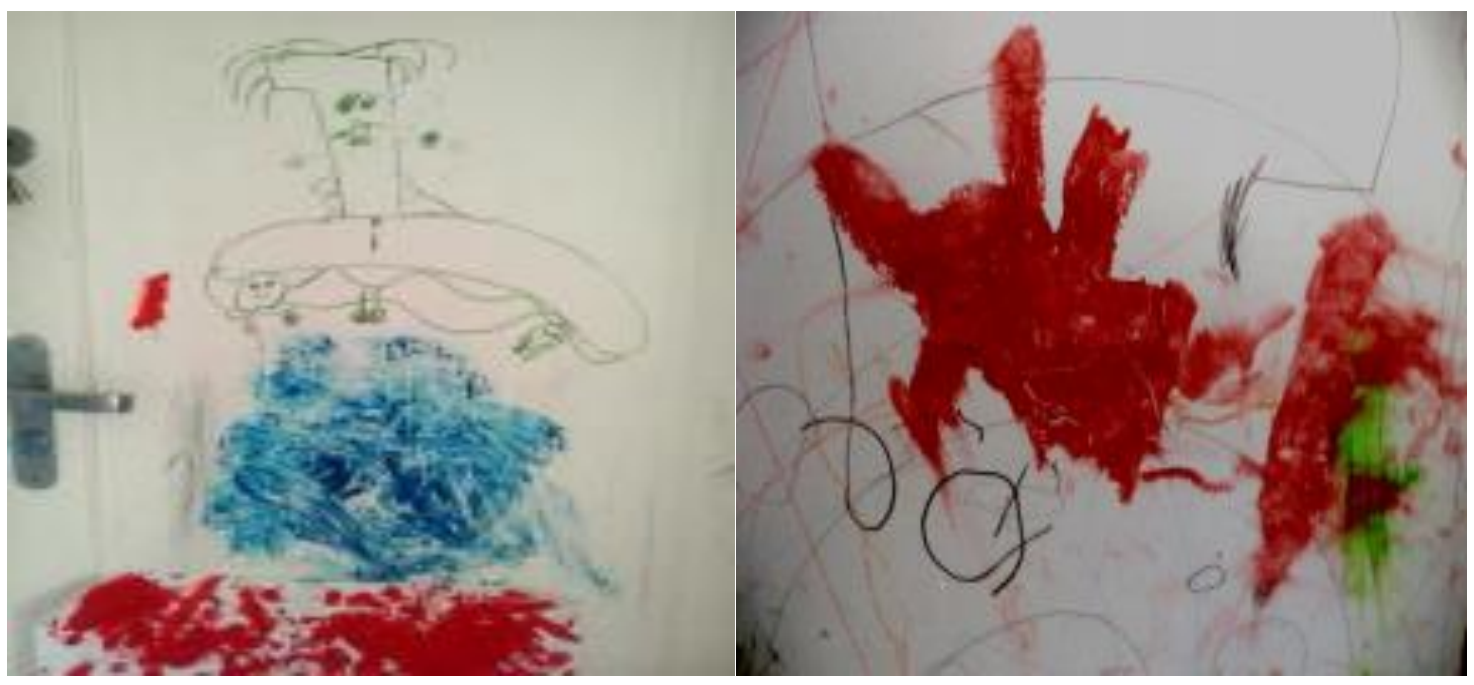

Fonte: Arquivo pessoal (s.d.).

A partir daí, começou a desenhar com os materiais que foi descobrindo: giz, tinta, cola, canetinhas e até batons que encontrava na bolsa da mãe.

$O$ desenho em casa foi permitido, desde o início. Acompanhamos 0 desenvolvimento do Pedro Aurélio, através dos desenhos nas paredes. Decidimos preservar a necessidade humana de registrar nas paredes, que nosso filho demostrou desde muito cedo. Seus registros feitos pelas paredes da casa deverão ser apagados, para receber novas cores e quem sabe novos desenhos. Esta experiência será preservada e compartilhada em um livro que deverá sair em breve, com as histórias, desenhos e memórias da primeira fase 
da vida do nosso filho Pedro Aurélio.

A expressão infantil deve ser preservada no momento que surge, caso contrário, não será expressa, pois as crianças crescem e se tornam adultas, portanto através deste estudo, da experiência como professora e da rica experiência de mãe, tenho defendido a livre expressão das crianças em suas casas e nas escolas. Sejamos os delbatores de nosso tempo, as paredes podem ser pintadas, mas a expressão infantil não se repete.

Convido os educadores e pais para que tenham coragem de exercitar em suas escolas e casas, a tarefa de delbatores, preservando espaço para as crianças desenharem livremente, em um movimento, que para alguns pode parecer vandalismo, mas que na sua integridade representa o que nos humanos já expressamos anteriormente nas cavernas, muros e paredes, a ideia de que: eu existo.

\section{CONSIDERAÇÕES FINAIS}

Neste trabalho discutiu-se e apresentou-se a história do desenho-grafite, relatos sobre artistas e suas obras expressas pelos muros da cidade de São Paulo, representações e manifestações artísticas focado na realidade do próprio autor, bem como possíveis caminhos didáticos para que as famílias, a escolas e sociedade em geral possam explorar a criatividade das pessoas representadas pela arte e pelos simples recursos que essa ação implica além de valorizar a arte, cultura e toda a história humana que essa expressão cultural permite.

\section{REFERÊNCIAS BIBLIOGRÁFICAS}

EPSTEIN, Issac. O Signo. São Paulo: Editora Ática, 1990.

FUSARI, Pedro Paulo. Cultura Popular na Antiguidade Clássica. São Paulo: Contexto, 1989.

GITAHY, Celso. (orgs e curador). ALAMEDA / Arte de Rua. São Paulo: Centro Cultural da Juventude, 2008.

MALDONADO, Mario. O desfio da comunicação: Caminhos e Perspectivas. São Paulo: Palas Athenas, 2004.

REVISTA RAP BRASIL GRAFFITI. № 23. São Paulo: Escala, 2004. 
REVISTA RAP BRASIL. Especial Graffiti. São Paulo: Escala, 2006. 